Studies in African Linguistics

Volume 23, Number 1, 1992-1994

\title{
ON THE SYNTAX OF POSSESSOR RAISING IN SWAHILI*
}

\author{
Camillia N. Keach \\ Temple University
}

\author{
Michael Rochemont \\ University of British Columbia
}

\begin{abstract}
Traditionally Possessor Raising (PR) in Swahili is included with a variety of sentence types as an instance of the Nominal Construction and more recently defended as a member of that class. This study has two major goals: first, it demonstrates that PR has syntactic distributional patterns which argue against its inclusion in the Nominal Construction. Secondly, it addresses a central question: what features of an explicit grammar explain the syntactic properties associated with PR? After showing that the inferentially based proposals in Hinnebusch and Kirsner [1980] and in Scotton [1981] do not adequately characterize PR nor accommodate its syntax, semantics or interpretation, we present a Government Binding treatment of PR's syntax. Finally, we provide a summary of our cross-linguistic research on PR's interpretation.
\end{abstract}

\section{The Problem*}

Traditional Swahili grammarians like Ashton [1944], Loogman [1965], and Polomé [1967] assemble sentences containing bare postverbal nominals into a natural class labelled here the NOMINAL CONSTRUCTION, adopting Ashton's terminology. By bare nominal they mean a postverbal nominal which is not morphologically related to the verb through the use of a verbal extension or prepositional case marker. Included within the Nominal Construction is Possessor

\footnotetext{
* The Swahili data in this study come primarily from fieldwork in Mombasa, Kenya conducted in 1990. Keach is indebted to the Social Research Council and to Temple University, and Rochemont to the Social Science and Humanities Research Council of Canada (grant no. 410-89-1239) for the funding which enabled our research and this paper. Appreciation is also due to our Swahili informants, Shiekh Nabhany, Samira Fakih Carey and John Mwana for their generous help with the data. This paper has benefitted from the comments of Russ Schuh, Robert Botne and two anonymous SAL reviewers. The usual disclaimers apply.
} 
Raising (PR), which often conveys an inalienable possession inter-pretation as in the Swahili sentences below.

\section{(1) a. ni-li-m-songoa Juma shingo 1 \\ I-PST-1-twist 1Juma 9neck \\ 'I twisted Juma's neck.'}

b. Juma a-li-m-kata Asha kidole

1Juma 1-PST-1-cut 1Asha 7 finger

'Juma cut Asha's finger.'

We focus on PR for several reasons. First, as we show in section 2, PR shows a range of particular syntactic properties which we take as a challenge to characterize. Our account of PR is given in section 5. Secondly, these properties set PR apart from other members of the Nominal Construction as we shall see in section 3. Finally, section 4 shows that the properties of PR are not adequately characterized in the treatments of this construction given in Hinnebusch and Kirsner [1980] and Scotton [1981], which assume the grammatical coherence of the Nominal Construction and which attempt to provide a semantic/pragmatic account, outside sentence grammar, for the inalienable interpretation associated with PR.

\section{The Syntactic Properties of PR}

We adopt the term "host" to refer to the inanimate bare nominal which is semantically related to the possessor and to the verb. Nevertheless, no morphological marking links the host to the possessor or to the verb. In fact, under PR the possessor assumes the canonical object properties usually associated with the host. This section presents the kinds of behaviors PR permits the possessor.

1 The numbers preceding nouns and their modifiers indicate noun class affiliation. Verbal morphology for third person will display numbers according to noun classes. First and second persons will be glossed by the corresponding English pronoun. Other abbrevitions used here are the following:
APPL applicative
CAUS causative
PASS passive
$\begin{array}{llll}\text { PST } & \text { past } & \text { S } & \text { singular } \\ \text { PRES } & \text { present } & \text { P } & \text { plural }\end{array}$
REL relative
STAT completion/resultant state (Ashton, p.37)

Generally the transcriptions of the languages other than Swahili include the glosses of the cited sources. 
2.1. Agreement. Agreement provides an excellent example of the possessor's elevated status. Normally, say in the genitival (quasi-)paraphrase of PR in which the host heads the NP, the host controls the object marker, as in (2a) and (3a). ${ }^{2}$ But under PR, the possessor controls the object marker, as in (2b-c), (3b-c).

(2) a. Juma a-li-(ki)-ata kidole cha Asha

1Juma 1-PST-(7)-cut 7finger 7-of 1Asha

'Juma cut Asha's finger.'

b. Juma a-li-m-kata Asha kidole

1Juma 1-PST-1-cut 1Asha 7finger

'Juma cut Asha's finger.'

c. *Juma a-li-(ki)-kata Asha kidole

'Juma cut Asha's finger.'

(3) a. ni-li-(zi)-chana nywele za Adija

I-PST-(10)-comb 10hair 10-of 1Adija

'I combed Adija's hair.'

b. ni-li-m-chana Adija nywele

I-PST-1-comb 1Adija 10hair

'I combed Adija's hair.'

c. *ni-li-(zi)-chana Adija nywele

'I cut Adija's hair.'

2.2. NP Movement. In the passive construction the host-headed genitival NP becomes the subject of a passive verb, as shown in (4a) and (5a). But under PR the possessor, not the host, assumes that position.

(4) a. miguu ya mtoto a-li-funik-wa 4legs 4-of 1child 1-PST-cover-PASS

'The legs of the child were covered.'

b. mtoto a-li-funik-wa miguu

1child 1-PST-cover-PASS 4legs

'The child's legs were covered.'

2 In Swahili, inanimate objects optionally agree with the verb, while object agreemeent is obligatorily present when the object is from one of the animate noun classes. 

${ }^{*}$ miguu i-li-funik-war mtoto
4legs 4-PST-cover-PASS 1child
'The child's legs were covered.'

(5) a. kidole cha Asha ki-li-kat-wa na Juma

7 finger 7-of 1Asha 7-PST-cut-PASS by 1 Juma

'Asha's finger was cut by Juma.'
b. Asha a-li-kat-wa kidole na Juma
1Asha 1-PST-cut-PASS 7finger by 1Juma
'Asha's finger was cut by Juma.'
c. *kidole ki-li-kat-wa Asha na Juma 7 finger 7-PST-cut-PASS 1Asha by 1Juma
'Asha's finger was cut by Juma.'

2.3. Relativization. Yet the host shows mobility with respect to $A^{\prime}$ movement in that it, as well as the possessor, may head a relative clause, as (6) and (7) illustrate.

(6) a. miguu a-li-yo-m-funika mtoto 4legs 1-PST-4REL-1-cover 1child 'The legs of the child which s/he covered'

b. mtoto a-li-ye-m-funika miguu 1child 1-PST-1REL-1-cover 4legs

'The child whose legs s/he covered'

(7) a. kidole ni-li-cho-m-kata msichana 7finger I-PST-7REL-1-cut 1-girl

'The finger of the girl which I cut'

b. msichana ni-li-ye-m-kata kidole 1-girl I-PST-1REL-1-cut 7finger 'The girl whose finger I cut'

2.4. Subject position. PR occurs postverbally, not in subject position.

(8) a. a-li-m-funika mtoto miguu 1-PST-1- cover 1child 4legs 'S/he covered the child's legs.' 
b. *mtoto miguu a-li-funik-wa 1child 4legs 1-PST-covered-PASS

'The child's legs were covered.'

In summary, Possessor Raising in Swahili is characterized as follows:

(9) (i) no morphology introduces the host;

(ii) only the possessor agrees with the verb, passivizes and is adjacent to the verb;

(iii) PR fails in subject position, and

(iv) both the host and the possessor may head a relative clause.

\section{PR and the Nominal Class}

This section presents evidence that sentence tokens cited as members of the Nominal Construction differ in one respect or another from the properties of PR as given in (9). Our demonstration will often hinge on a comparison of the contrasting behavior of the host in PR and its counterpart in the Nominal Construction.

Sentences like those in (10) through (14) are often cited as members of the Nominal Construction; (10) and (11) contain bare postverbal instrumentals; (12) is an instance of Locative Inversion, a construction in which a locative phrase is preposed showing subject agreement with the verb and the verb's logical subject occurs postverbally3; examples (13) and (14) contain a postverbal nominal which, according to Ashton, "adds some detail in respect to the action or state expressed by the [intransitive] verb, whether in time, place, manner or reason, etc." (p. 299).

(10) Juma a-li-m-piga mzizi jiwe [Whiteley 1972:18] 1Juma 1-PST-1-hit 1thief 5stone 'Juma hit the old man with a stone.'
(11) Juma a-li-u-ka-za mzigo kamba
[Scotton 1981:162]
1Juma 1-PST-3-tie-CAUS 3load 9rope
'Juma tied the load with a rope.'

(12) sokoni ku-na-uza wanawake

[Scotton 1981:166] market-17 17-PRES-sell 2women 'Women are selling at the market.'

3 The interested reader is refered to the LFG analysis of this construction in Chichewa given in Bresnan and Kanerva [1989]. 
(13) Juma a-li-ondoka mnyonge

[Abdulaziz 1976:153]

1Juma 1-PST-leave 1 humble person

'Juma left (as) a humble person.'

(14) watu wa-me-ingia vumbi

2people 2-STAT-enter 5dust

[Whiteley 1972:22]

'The people are dusty.'

We begin the comparison with the bare instrumentals in (10) and (11). We noted earlier that a property of PR is that the host may not be associated with any morphological marking. However, as pointed out in Vitale [1981], the bare instrumentals jiwe and kamba above may be preceded by $k w a$, as shown below.

(15) a. a-li-m-funga Juma kwa kamba

1-PST-1-tie 1Juma with 9rope

'S/he tied Juma with a rope.'

b. Juma a-li-u-ka-za

mzigo kwa kamba

1Juma 1-PST-3-tie-CAUS 3load with 9rope

'Juma tied the load with a rope.'

Furthermore, in the absence of the agent phrase, the instrumental can appear as the subject of the active verb (15c), whereas in PR the host may not occur as a subject (15d).

(15) c. kamba i-li-m-funga Juma

9rope 9-PST-1-tie 1Juma

'A/the rope tied Juma.'

d. *kichwa ki-li-m-piga Juma

7head 7-PST-1-hit 1Juma

'Juma's head was hit.'

Unquestionably the predicate nominal in (12) and the locative inversion construction in (13) differ semantically. Nevertheless, we can illustrate that their syntactic behavior is similar in two respects and that it departs from that of PR. First, we showed earlier that under PR both the host and possessor may relativize. However, neither the predicate nominal nor the postverbal nominal in a Locative Inversion construction may relativize. 
(16) *hawa ndiwo wanawake sokoni ku-na-wo-usa

2these 2-be 2women market-17 17-PRES-2REL-sell

'These are the women who sold at the market.'

(17)

*huyu ndiye mnyonge a-li-ye-ondoka mtu

1this 1-be 1humble person 1-PST-1REL-leave 1person

'This is the humble person who left (as) a man.'

Secondly, recall that under PR the active verb obligatorily contains an object marker agreeing with the animate possessor; yet (18) and (19) show that in Locative Inversion and the Predicate Nominal, an object marker is obligatorily absent even though an animate NP follows the verb in both cases.

(18) *sokoni ku-na-wa-uza wanawake

market-17 17-PRES-2-sell 2women

'Women sold at the market.'

(19) *Juma a-li-mw-ondoka mnyonge

1Juma 1-PST-1-leave 1humble person

'Juma left (as) a humble person.'

Scotton [1981] cites (14) as an example of the Extensive Case (see section 4.2). Although only the possessor, not the host, may passivize under PR, two passive versions of (14) are possible, as shown in (20).
a. vumbi li-me-ingi-wa
na watu
5dust 5-STAT-enter-PASS by 2people
'The people are dusty.'
b. watu wa-me-ingi-wa na vumbi 2people 2-STAT-enter-PASS by 5dust
'Dust covers the people.'

This subsection has presented some of the syntactic contrasts available between PR and several of the cases traditionally subsumed with it under the rubric of the Nominal Construction. We believe we have demonstrated two things: first, that there is substantial evidence that the distributional properties of PR differ from those of the instrumental, locative inversion, the predicate nominal, and the construction in (14), and secondly that the properties of PR depart substantially enough from other Nominal Constructions to warrant PR as having its own 
status. We conclude that the Nominal Construction can not be a natural syntactic class in Swahili grammar if it includes PR. ${ }^{4}$

\section{Previous treatments}

The next two subsections present the analyses in Hinnebusch and Kirsner [1980] and in Scotton [1981] of the inalienable interpretation often associated with PR. The third subsection contains our objections to their proposals.

4.1 The Inferential Account. Hinnebusch and Kirsner (hereafter H\&K) assume that the lack of overt morphological cues in the Nominal Construction requires that the interpretation of the bare nominals be outside sentence grammar and, hence, inferred. Apparently, the syntax of PR is due to its being a member of the Nominal Construction since H\&K do not discuss the syntax of PR. They provide a means of explaining the interpretations of (21) where PR is acceptable in inalienable contexts but unacceptable in alienable contexts.

a. ni-li-m-vunja Juma mguu 5

I-PST-1-break 1Juma 3leg

'I broke Juma's leg.'

b. *ni-li-m-vunja Juma kiti

I-PST-1-break 1Juma 7chair

'I broke Juma's chair.'

They make the following assumptions: (1) morphology signals an invariant meaning, and with little morphological information, the hearer will infer an obvious message; (2) subject agreement signals primary focus of attention; and (3) object agreement signals secondary focus of attention.

$\begin{array}{llll}\text { (22) } & n i- & \text { li- } & m \\ & \text { FOCUS } & \text { 2ND FOCUS } & \\ & & \text { LESS ACTIVE }\end{array}$

breaker

breakee

\footnotetext{
4 Indeed this section has called into question the coherence of the Nominal Construction even if it does not include PR. And while it is far beyond the scope of this paper to discuss how GB might analyze these residual constructions, the interested reader may refer to Baker's [1988b] GB analysis of instrumentals and locatives for Chichewa and to the highly suggestive proposals in Freeze [1992] and Kayne [1993].

5 Our informants insist, contra H\&K, that PR sentences like (21) are not ambiguous between an alienable and an inalienable interpretation, but rather strictly encode an inalienable interpretation. See also Scotton's discussion in section 5.4 of her paper.
} 
The verb "break" relates the bare lexical items to the event such that "Juma" can be the breakee if the "leg," an inalienable body part, is attached to him. However, the chair may not be related to the event in the same way.

4.2. The extensive case account. While the inferential account locates the interpretation of host-NP in PR entirely in the pragmatics, Scotton's [1981] proposal inserts a grammatical layer between the sentence types in the Nominal Construction and their (pragmatic) interpretations. Specifically, Scotton proposes that Swahili grammar has a syntactic position reserved for nominals which receive the Extensive Case (EC hereafter). EC's, like the host-NP in PR, occur in the following positions:

$$
\begin{aligned}
& \text { i. NP1 (agent) + verb + NP2 (patient) + NP3 (extensive) } \\
& \text { ii. NP1 (patient) + verb + NP2 (extensive) } \\
& \text { iii. NP1 (locative) + verb + NP2 (extensive) }
\end{aligned}
$$

In the semantics, all EC nominals receive a uniform semantic characterization which "... particularize the extent to which the action or state referred to by the main verb applies to the patient." (p.160) In other words, from the variety of interpretations available for EC nominals, the pragmatics will determine the specific interpretation accorded an EC nominal in the sentence token that contains it.

4.3. A critical discussion. We agree with a tacit assumption made in both studies. It is very unlikely that the Swahili verb has an inalienable possessor thematic-role to assign to the postverbal argument in PR. To illustrate this point consider (24) where the object of the verb can fulfill only the theme/patient role.

$$
\begin{aligned}
& \text { a. } \text { *ni-li-m-kata Juma } \\
& \text { I-PST-1-cut 1Juma } \\
& \text { 'I cut Juma's.' }
\end{aligned}
$$

b. *ni-li-m-kat-i-a Juma Asha

I-PST-1-cut-APPL-FV 1Juma 1Asha

'I cut Asha's for Juma.'

The possessional reading occurs only when the NP interpreted as the possessor cooccurs with the theme, as in (25).

(25) a. ni-li-m-kata Juma kidole I-PST-1-cut 1Juma 7finger 'I cut Juma's finger.' 


\section{b. ni-li-m-kat-i-a Juma Asha kidole I-PST-1-cut-APPL-FV 1Juma 1Asha 7finger 'I cut Asha's finger for Juma.'}

However, neither study addresses this co-dependency in PR which we believe must be addressed in a successful treatment of the construction's interpretation.

Our first objection to the inferential and EC accounts concerns the characterization of PR sentences as members of the Nominal Construction. In the previous section we have demonstrated that PR's syntactic distribution departs substantially from that of the sentences from the Nominal Construction in (10) through (14).

Secondly, neither account provides an explanation for the syntactic properties of PR that we have isolated here. Specifically, the treatment of passive is unsatisfactory. The EC account stipulates that when an EC nominal becomes the subject, its EC case changes to the patient case, giving rise to the template in (23) ii. We wonder whether all semantic cases including "agent" may shift? If not, why not? If so, what overall function do semantic cases serve in the grammar that includes them? As for an account which infers the interpretation of the host-NP from PR surface strings, H\&K seem forced to provide a treatment for the interpretation of passive PR sentences that infers the relation between the host and the possessor NP in subject position. This treatment must differ from their analysis of passive for non-PR sentences where the subject is not interpreted as the possessor. Furthermore, we saw in the previous section that PR is blocked in subject position. Neither the inferential nor the EC account provides an explanation for PR's failure in this purely grammatical context.

A third criticism concerns the nature of their semantics. As it turns out, "patient" refers simply to NP1 of a single argument verb and NP2 of a transitive verb, regardless of the semantic/thematic-role assigned. For instance, in (26a) 'leg' as the head of 'leg of Juma' is the patient. But, in (26b) 'leg' is in the extensive case and Juma is the "patient".

a. ni-li-u-vunga mguu wa Juma

I-PST-3-break 3leg 3-of 1Juma

'I broke Juma's leg.'

b. ni-li-m-vunja Juma mguu

I-PST-1-break 1Juma 3leg

'I broke Juma's leg.'

Evidently, 'leg' is not the "patient" in both these examples, although it is broken in both cases. This might not appear so damaging in this case, but the difference is brought out more clearly in the following example. 
(27) a. mganga a-li-ondoa risasi ya Juma

1doctor 1-PST-remove 9bullet 9-of 1Juma

'The doctor removed Juma's bullet.'

b. mganga a-li-mw-ondoa Juma risasi

1doctor 1-PST-1-remove 1Juma 9bullet

'The doctor removed Juma's bullet.'

Both accounts must claim that while 'bullet' is the patient/theme of the verb in (27a), it is 'him' that is the patient/theme in (b), and 'bullet' is in the extensive case (and/or whose meaning is inferred). However, if we adopt these proposals and assume that kuondoa assigns the patient thematic-role to NP2, then (27b) receives a non-sensical interpretation in which Juma is removed, rather than the bullet from him. Thus, it is clearly evident that the term "patient" is not consistent with nor equivalent to the thematic notion of patient/theme.

Finally, an account that relies as crucially on pragmatics and inference as these do just can not work for several reasons. First of all PR is not forced solely by the lexical content of the postverbal nominal such that only body parts cooccur with their hosts as bare nominals in this construction. Indeed, as noted in the introductory section of their paper, H\&K demonstrate that NP's containing alienable possessions also provide lexical material that can undergo PR (our (29) below). However, it is not evident how their inferential account distinguishes (28) from (29) in which the possessed nominal is alienable.

(28) *ni-li-m-vunja Juma kiti

I-PST-1-break 1Juma 7chair

'I broke Juma's chair.'

(29)

a. Rosa a-li-nyang'any-wa shuka

1Rosa 1-PST-rip away-PASS 7shuka (article of clothing)

'Rosa had her shuka ripped off her.'

b. mganga a-li-mw-ondoa risasi

1doctor 1-PST-1-removed 9bullet

'The doctor removed his bullet.'

c. meza i-me-pangu-s-wa vumbi

9table 9-STAT-remove-CAUS-PASS 9dust

'The table was dusted.'

Moreover, in their discussion of (29c) H\&K imply that if the ownership relationship obtains, PR should be possible. However, there are cases where 
plausibility preserves the interpretation of ownership; yet, PR is impossible in such sentences. How does an inferential account permit an acceptable inference in (29c), but rule one out for (30)?

\section{a. *a-li-m-vunga mvuvi kisu}

1-PST-1-break 1fisherman $7 \mathrm{knife}$

'S/he broke the fisherman's knife.'

b. *ni-li-haribu mwanafunzi vitabu vyote

I-PST-ruin 1student 8books 8-all

'I ruined all of the student's books.'

Finally, Scotton contrasts the sentences in (31), saying of them that 'legs' is a member of a series which specifies extent as to the part of the patient to which the action applies and 'blanket' specifies the extent as to the manner in which the action gets accomplished.

a. *a-li-m-funika miguu

1-PST-1-cover 4legs

'S/he covered her/him with legs.'

[okay as: 'S/he covered her/his legs.']

b. *a-li-m-funika blanketi

1-PST-1-cover 9blanket

'S/he covered her/his blanket'

[okay as: 'S/he covered him with a blanket.']

However, nothing in either Scotton's or H\&K's system prevents the opposite interpretation in the unbracketed glosses above. Why MUST the sentences in (31) receive the inalienable and instrumental interpretations?

Similarly, neither account provides an explanation for why the other sentence types included in the Nominal Construction do not receive an inalienable reading. Scotton, for example, describes EC nominals as including IP (inalienable possession), locative, instrumental nominals, among others. However, there is no mechanism that we can determine that matches an EC to the appropriate interpretation, rather than to any of the other interpretations available for EC nominals. This comment extends to the inferential account as well. In short, these theories simply do not work sufficiently well to characterize the syntax, semantics or the pragmatics of PR. 


\section{A Government Binding Account of PR}

Our goal differs from that of Scotton and H\&K, who have sought to characterize the inalienable interpretation, virtually independently of the syntax of inalienable possession. We seek to determine how PR is syntactically licensed, by which we mean how a construction and the various distributional properties it manifests are properly characterized through the interaction of inde-pendently motivated principles of grammar. In this section, we present an explicit account within GB that accommodates our objections to the above studies and that addresses the central question of this study which we can now more cogently rephrase: how does GB explain the property of a construction containing an NP which does not receive a thematic-role from a verb but which nevertheless acts as an argument of the verb?

5.1 A morpholexical account. We begin by showing that a purely morpholexical account is inadequate to the task of licensing PR. The argument proceeds as follows. We assume causative and benefactive verbs are derived by morpholexical rules which add an argument to the base verb. Although these operations can convert a transitive into a ditransitive through the addition of verbal extensions, these operations may not convert a ditransitive into a tri-transitive. In fact there is no overt morpholexical operation in Swahili that can give rise to three bare postverbal nominals. Only in PR do we find what appears to be tritransitives. We conclude that PR can not be derived by morpholexical operations.

First, although the causative morpheme may convert a transitive verb like (32a) into the ditransitive in (32b), two causative morphemes may not derive the tritransitive causative in (32c).
a. Asha a-li-pika chakula
1Asha 1-PST-cook 7 food
'Asha cooked food.'

b. watoto wa-li-m-pik-isha Asha chakula

2children 2-PST-1-cook-CAUS 1Asha 7 food

'The children made Asha cook food.'

c. *Juma a-li-wa-pik-ish-isha watoto Asha chakula

1Juma 1-PST-2-cook-CAUS-CAUS 2children 1Asha 7food

'Juma made the children make Asha cook food.'

Yet double causatives are possible in Swahili as shown by the completely acceptable case below taken from Vitale [1981]. 


\section{(33) Yusuf a-li-m-saf-ish-isha Jahi chumba \\ Yusuf 3S-PST-him-clean-CAUS-CAUS Jahi 7room \\ 'Yusuf made Jahi clean the room.'}

Vitale further observes that "... the double lexical causatives which do occur are derived, for the most part, from underlying intransitive constructions since anything above a three-place predicate is marginally or totally unacceptable because of the number of adjacent NP's." [p.175-176].

Likewise, the applicative, which may derive a ditransitive benefactive, may not produce a tritransitive causative-applied verb in Swahili.

(34) *Juma a-li-wa-andik-ish-i-a watoto mwalimu barua Juma 1-PST-2-write-CAUS-APPL 2children 1teacher 9letter 'Juma made the children write a letter to/for teacher.'

In fact, neither the causative nor the benefactive morpholexical operations may apply to an underived ditransitive, thereby producing a tritransitive.

a. Asha a-li-m-pa Juma kitabu Asha 1-PST-1-give 1Juma 7book 'Asha gave Juma a book.'

b. *Ali a-li-m-p-esh-a Asha Juma kitabu Ali 1-PST-1-give-CAUS 1Asha 1Juma 7book

'Ali made Asha give Juma a book.'

c. *Ali a-li-m-p-e-a Asha Juma kitabu Ali 1-PST-1-give-APPL 1Asha 1Juma 7book 'Ali gave Juma a book for Asha.'

In summary, the morpholexical causative and benefactive operations can convert intransitive verbs into transitives, and transitives into ditransitives, but not ditransitives into tritransitives. Only in PR do we find tri-transitives like (36).

a. ni-li-m-chan-i-a Juma watoto nywele

I-PST-1-comb-APPL 1Juma 2children 9hair

'I combed the children's hair for Juma.'

b. ni-li-m-gus-i-a Asha Juma mkono

I-PST-1-touch-APPL 1Asha 1Juma 3arm

'I touched Juma's arm for Asha.' 
Moreover, as pointed out by an anonymous SAL reviewer, another reason for concluding that PR is not a morpholexical operation is that no overt morphology signals PR.

5.2 A syntactic analysis of PR. Drawing on proposals in Koopman [1987], Koopman and Sportiche [1988], and Carstens and Kinyalolo [1990], works which develop proposals in Chomsky [1981, 1986], we propose that the analysis of PR lies in the interaction of Case theory, Theta theory and the theory of phrase structure.

To begin let us see how assumptions from these works provide a derivation for a simple sentence in Swahili. A sentence like (37a) would begin its derivation as $(37 b) .6$

a. Asha a-li-m-gusa Juma 1Asha 1-PST-1-touch 1Juma 'Asha touched Juma.'

b.

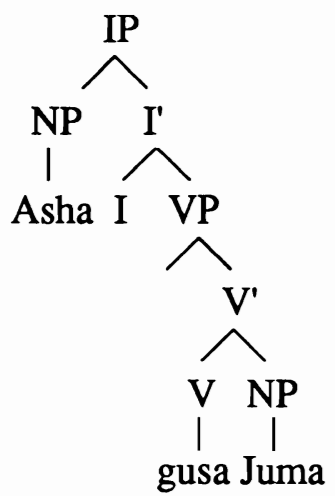

Each of the lexical elements in the d-structure (37b), in particular $V$ and $I$ (inflection), projects a structure that accords with the principles of $\mathrm{X}^{\prime}$ theory. The subject is base generated in the specifier of IP position, the canonical subject position. The object of the verb is generated in immediate postverbal position. It is at this d-structure level that the semantic role of the verb's arguments must be assigned. In GB theory this is expressed through the Theta Criterion which requires that each of the verb's semantic (thematic) roles be assigned to an appropriate phrase and that each argument in the structure be assigned a thematic role. In (37b), "Asha" receives the agent role in virtue of occupying the subject

${ }^{6}$ For ease of presentation in this paper, we are simplifying the analysis presented in Keach and Rochemont [1991b], Rochemont and Keach [1991] and modifying to some extent the theoretical assumptions drawn from the works cited. For more detail the reader is referred to these references. 
position and "Juma" receives the patient/theme role since it occupies the canonical object position.

(37) c.

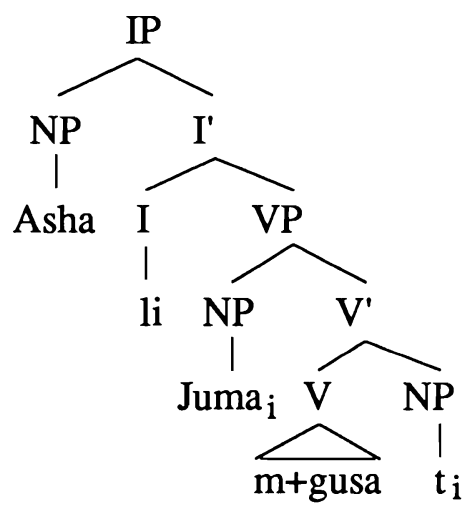

In the intermediate structure (37c), the object has raised to the specifier position of VP (leaving a trace at the extraction site), the position in which it receives Abstract Case and triggers agreement on the verb following the references cited above. This is also the position that phrases that undergo passive must occupy in order to be passivizable.

(37) d.

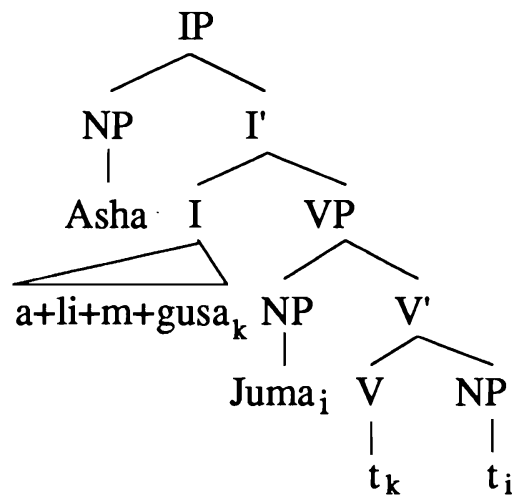

In the s-structure (37d), the verb has raised from its position in VP to I where it acquires the inflectional morphology associated with I. Once again, the subject and the verb, now in I, are in an agreement relation. Abstract Case for the subject is satisfied due to this relation. GB theory has an s-structure principle which mandates that all arguments in the structure must receive Abstract Case from an Abstract Case marking head. As we have just seen, this requirement is satisfied for the two arguments in (37), and in both cases, due to the specifier-head relation. 
Consider now how these theoretical assumptions apply in the analysis of PR. We have argued that the possessor in these cases is not thematically related to the verb. In this we follow the analytical approach to PR advanced in Massam [1985] and Baker [1988]. The simplest assumption for PR cases is that the possessor's theta-role is due to its relation to the host. Since the Theta Criterion is satisfied at $\mathrm{d}$-structure, GB theory suggests a d-structure of the sort in (38b) for the sentence (38a). ${ }^{7}$

a. Asha a-li-m-gusa Juma kidole 1Asha 1-PST-1-touch 1Juma 7finger

'Asha touched Juma's finger.'

b.

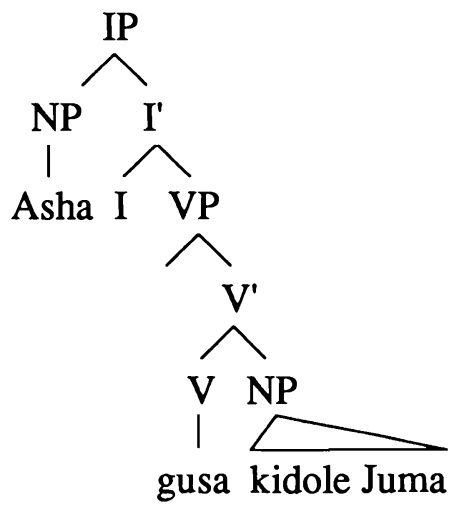

To characterize the object-like behavior of the possessor, we will assume that in PR constructions the possessor raises from its d-structure NP internal position to the structural object position in the specifier of VP, as illustrated below.

7 The structure of the NP in Swahili is a subject of some investigation, c.f. Carstens [1991]; Reynolds [1989]; Hawkinson [1979]. As it is not our purpose here to analyze NP structure, we do not intend to make any explicit proposal regarding the internal structure of NP's and accordingly remain uncommitted in the d-structure (38). 


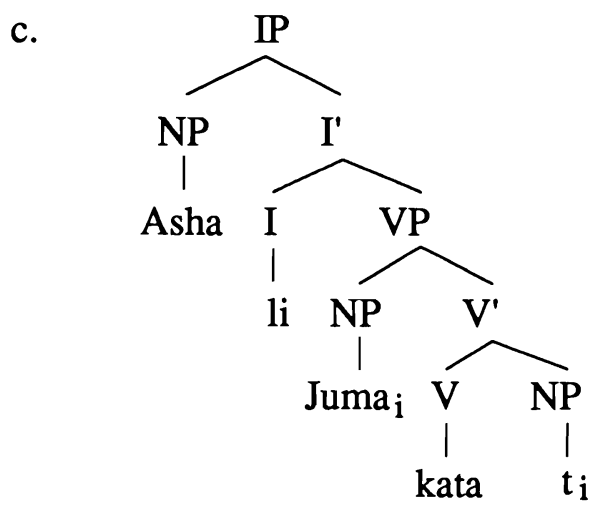

After $\mathrm{V}$ raising as in the earlier example, the intermediate structure above will give rise to a structure underlying the sentence in (38a).

Recall that it is the phrase that occupies the VP specifier position that may trigger agreement on the verb and that may passivize. Given that the VP has a unique specifier position, we properly characterize the object marking and passivization properties of PR. In particular, only the possessor may passivize or object mark in such cases. Notice that the Theta Criterion is satisfied for the possessor due to its d-structure relation to the host, and for the host, by virtue of its d-structure object relation to the verb. The case requirement is satisfied for the possessor because of its specifier-head relation to V (as for the object in (37)), and for the host by virtue of inherent case assignable only to phrases already in a thematic relation to the verb. The further property of PR that either the host or the possessor may relativize follows from the assumption that relativization in Swahili does not require movement through the specifier of VP. ${ }^{8}$

What stops the host nominal from raising to the Spec of VP and stranding the Possessor giving rise to the illformed sentence below in (39a)?
a. *Asha alikata kidole Juma
b. *kidole kilikatwa Juma (na Asha)

Following Chomsky [1986] we assume that only heads and maximal projections may undergo movement. Since in our analysis the Possessor NP (a maximal projection) moves into the government domain of the verb, the host (also a

\footnotetext{
8 We note that on the account given here relativization of the host leads to a violation of the proper binding condition which may be avoided in various ways: by adopting an analysis of inalienable possession of the type proposed in Yoon [1990] (see note 12); by assuming that in Swahili the host in N' may relativize; or by assuming reconstruction at LF for A' level movement operations. 9 Baker [1988] pursues an analysis of PR in which the host-head incorporates into the verb. Keach and Rochemont and Rochemont and Keach's discussion of Bantu object symmetry and asymmetry reveal difficulties that an incorporation analysis would impose on Bantu grammar overall.
} 
maximal projection) may not move without also taking along the syntactically dependent possessor. Moreover, movement of the host into subject position of the passive verb as in (39b) would constitute a proper binding condition violation whereby the subject NP contains a trace that c-commands its antecedent, as shown in (40).

(40)

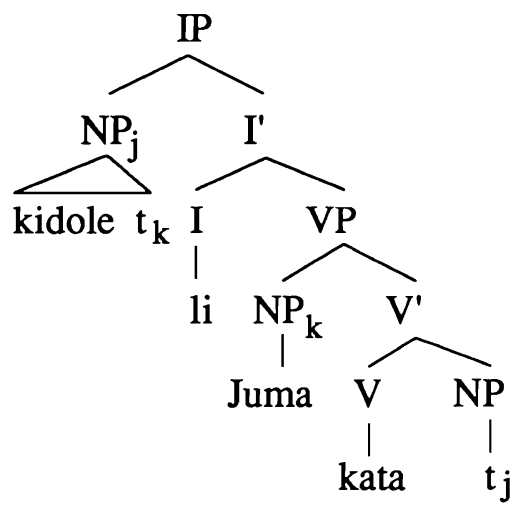

Finally notice that an NP internal possessor may not relativize without passing through specifier-VP because that would lead to a violation of subjacency. ${ }^{10}$ This analysis provides a syntactic characterization of Possessor Raising.

\section{The Inalienable Interpretation}

We begin this section with two observations concerning the semantics of PR. First, the NP to be explained in our account differs from the problematic NP in the inferential and EC treatments. Because those proposals analyze the possessor $\mathrm{NP}$ as directly theta-related to the verb as secondary Focus or as the theme/ patient, the interpretation of the host requires an explanation in the EC and Inferential accounts. In our account it is the interpretation of the possessive nominal in PR that requires an explanation, not its host, since the host satisfies the selectional restrictions associated with the verb's theme/patient thematic-role. Second and more importantly, if we assume that verbs do not directly assign a possessional theta-role at all, 11 as the evidence suggests, then this study resurrects the question probed in the inferential and EC accounts: how does an explicit grammar account for the interpretation associated with PR?

10 The analysis just outlined for the core cases of possessor raising can be extended to accommodate the morpholexical examples in the first part of this section under specific assumptions concerning the nature and distribution of structural and inherent case. For a specific proposals see Keach and Rochemont [1991a] and Keach (in preparation).

11 We might suppose that the possessor gets its thematic-role inside NP. See Williams [1981], Di Sciullo and Williams [1987], and Grimshaw [1990] for discussion. 
We confess our inability to address this issue satisfactorily here. And as we have argued here the previous accounts provide no successful account either. However, our research has uncovered a cluster of generalizations, some heretofore unobserved in the literature, that might guide further research toward an insightful analysis.

First, we repeat the observation made in section 4.3. that there is a codependency between the possessional reading and the presence of a lexically overt theme. How is the required presence of the theme associated with the interpretation of PR? 12

Secondly, PR appears to signal not simply inalienable possession, but more broadly a part-whole relationship, as often noted. Consider the following PR sentences from Swahili.

(41) a. ni-li-(i)-vunja meza miguu miwili

I-PST-(9)-break 9table 4leg 4two

'I broke two of the table's legs.'

b. wa-li-(li)-saf-isha gari magurudumo

2-PST-(5)-clean-CAUS 5car 6wheels

'They cleaned the car's wheels.'

c. ni-me-(li)-vunja birika mkono

I-STAT-(5)-break 5vessel 3handle

'I have broken the vessel's handle.'

d. ni-me-(ki)-fanya kiti miguu

I-STAT-(7)-make 7chair 4legs

'I have made the chair's legs.'

The sentences in (41) display the familiar distributional pattern we have seen in cases of PR involving inalienable possession: the possessor controls the object marker, optional here since the possessor is inanimate, but the host does not; the possessor may be the subject of the passive verb while the host may not. Voeltz

12 Yoon [1990] addresses this issue and the question of the semantic class of verbs that allow PR in his GB analysis of the interpretation of inalienable possession constructions in Mandarin, French and Korean. He proposes that the body part and inalienable possessor NP's share a single theta-role via Theta Identification, a modification relation. While his account can be adopted for the canonical cases of Swahili inalienable possession involving body parts, it is not readily apparent what further assumptions might be necessary to distinguish between sets of data like those in (28) and (29) where the possessions are all alienable, but where PR is possible only in (28). Even if a single modification could account for such data, it is unlikely that it could subsume the issues raised in this remainder of this section. 
[1976] provides a number of similar examples from Sotho like the ones below in (42) where a part/whole relationship obtains between the post-verbal nominals.

(42) a. Palesa okhaola sefate makala/*selepe

P. cuts tree branches/axe

b. P. obetia pene motsu/*lebare

P. sharpens pen tip/razor blade

We conclude with Voeltz [1976], Hyman [1977], and Scotton and Whiteley [1968, 1972] that the part/whole relation may be a more precise characterization of the relation that obtains between the bare nominals in the PR construction than inalienable possession. Third, an account of the interpretation of PR will address the fact that only a specific class of verbs can give rise to PR even when the part/whole relation is satisfied (43a), and in some cases where it appears not to be, as in (43b) through (43d).

(43) a. [Swahili]

*Juma a-li-mw-ona Asha miguu

1Juma 1-PST-1-see 1Asha 4legs

'Juma saw Asha's legs.'

b. [Swahili: H\&K p.3]

Rosa a-li-nyang'any-wa shuka

1Rosa 1-PST-rip-PASS 9shuka

'Rosa had her shuka ripped off her.'

c. [Haya: Hyman [1977]]

n-ka-teemul'ómwáán' éshaati

SM-P3-tear child shirt

'I tore the child's shirt.'

d. [Kinyarwanda:Kimenyi [1978]]

umujura y-aa-ny-ib-ye igitabo

thief SM-PST-1/SO-steal-asp book

'The/a thief stole my book.'

Massam [1985:342] notes that Korean verbs such as ppaas 'deprive', karochae 'usurp', thol 'rob', and ttut 'rip off' allow a genitive possessor to passivize to subject. Moreover, in a survey of the Possessor Stranding in Iroquoian languages, Baker suggests that Possessor Stranding must be governed in one of two ways: the verb must be a transfer of possession verb (e.g. 'steal', 'buy', 'find' ...), or the noun must take an inalienable rather than an alienable possessor. A satisfying 
analysis of the interpretation of PR would address the fact that for some semantic class of verbs, PR is possible whether or not the NP's are in a partwhole/inalienable relation.

And finally, any account of PR's interpretation will come to grips with a glaring but unrecognized generalization revealed in our research. There appear to be no instances of PR with ONLY an inalienable or part/whole reading that cooccur with overt verbal morphology. What we do find are possessor raising cases where the verb is overtly morphologically marked and where there is no restriction to a part-whole/inalienable relation between the bare nominals.

(44) a. [Kinyarwanda: Kimenyi p. 98]

umhuungu a-ra-som-er-a umukoobwa igitabo

boy he-PRES-read-APPL-ASP girl book

'The boy is reading the girl's book.'

b. [Chichewa: Baker p. 271]

fisi a-na-dy-er-a kalulu nsomba

hyena SP-PAST-eat-APPL-asp hare fish

'The hyena ate the hare's fish.'

c. [Chamorro: Baker p. 272]

ha f'gasi-yi yu'si Flory ni magagu-hu

3S-wash-APPL me PN Flory obl clothes-my

'Flory washed my clothes.'

d. [Choctaw: Baker p. 272]

naahollo-ya tobi i-m-apa-li-tok

whiteman-acc bean 3S-APPL-eat-I-PST

'I ate the white man's beans.' OR 'I ate green beans.'

In sum, we hope that a treatment of PR's interpretation would not only explain such cross-linguistic observations, but would also wed that explanation to an explicit syntactic treatment, such as the one proposed.13

13 A highly suggestive possibility is that particular extractions from NP might be made sensitive to a part/whole requirement. For exammple, Cattell [1979] observes that wh- extraction of adjuncts from NP in English does display this restriction.

(i) which car do you like the brakes in?

(ii) *which car do you like the girl in? 


\section{Conclusion}

To summarize, we have argued that PR displays a coherent set of syntactic properties which distinguish it from the Nominal Construction. We have shown further how an analysis guided by GB assumptions might account for those properties. In this account, the constrained mechanisms in the GB framework, specifically X-bar, theta-, case and movement theories, interact in such a way as to provide an explanation for the syntactic properties associated with PR.

\section{REFERENCES}

Abdulaziz, Mohamed H. 1976. "Transitivity Patterns in the Swahili Clause." Unpublished Ph.D. dissertation, University of London, London.

Ashton, E. 1944. Swahili Grammar. London: Longman.

Baker, M. 1988a. Incorporation: A Theory of Grammatical Function Changing. Chicago: University of Chicago Press.

Baker, M. 1988b. "Theta Theory and the Syntax of Applicatives in Chichewa." Natural Language and Linguistic Theory 63:741-782.

Bresnan, J. and L. Moshi. 1990. "Object Asymmetries in Comparative Bantu Syntax." Linguistic Inquiry 21:147-185.

Carstens, V. 1991. "The Morphology and Syntax of Determiner Phrases in KiSwahili." Unpublished Ph.D. dissertation. UCLA.

Carstens, V. and K. Kinyalolo. 1990. "On IP Structure: Tense, Aspect and Agreement." Unpublished ms. UCLA.

Cattell, R. 1979. “On Extractability from Quasi-NPs.” Linguistic Inquiry 10:168172.

Chomsky, N. 1981. Lectures in the Theory of Government and Binding. Dordrecht: Foris. 
Chomsky, N. 1986. Knowledge of Langage. New York: Praeger.

Chomsky, N. 1992. “A Minimalist Program for Linguistic Theory.” ms. MIT.

Di Scuillo, A. M. and E. Williams. 1987. On the Definition of Word. Linguistic Inquiry Monograph 14. Cambridge: MIT Press.

Grimshaw, J. 1990. Argument Structure. Linguistic Inquiry Monograph 18. Cambridge: MIT Press.

Hawkinson, A. 1979. "Homonymy versus uunity of form: the particle -A in Swahili." Studies in African Linguistics.10:81-109.

Hinnebusch, Thomas J. and Robert S. Kirsner. 1980. "On the inference of 'inalienable possession' in Swahili." Journal of Linguistics and African Languages 3:37-81.

Hyman, L. 1977. "The syntax of body parts." In E. Byarushengo, A. Duranti, and L. Hyman (eds.), Haya Grammatical Structure, pp. 99-117. (SCOPIL 6) Los Angeles: University of Southern California.

Hyman, L., D.K. Alford, and E. Akpati. 1970. "Inalienable possession in Igbo." Journal of West African Languages 7:85-101.

Keach, C. N. Barrett. 1986. "Word-Internal Evidence from Swahili for Aux/ INFL.” Linguistic Inquiry 17: 559-564.

Keach, C. N. Barrett. 1987. "Phonological Allomorphy in Swahili: on the Form of Inanimate Pronominal Clitics." Studies in African Linguistics 18:263-298.

Keach, C. N. Barrett. (in preparation). "PR in Bantu Applied Benefactives."

Keach, C. N. Barrett and M. Rochemont. 1991a. "Case Questions from Swahili." Paper presented at the University of Pennsylvania.

Keach, C. N. Barrett and M. Rochemont. 1991b. "Symmetry, Case and Agreement in Bantu." GLOW Newsletter 28, Tilburg University, the Netherlands.

Keach, C. N. Barrett and M. Rochemont. 1992. "Asymmetry in Symmetrical Object Languages: a Problem for LFG?” ms. Temple University. 
Kimenyi, A. 1980. A Relational Grammar of Kinyarwanda. Berkeley: University of Caliornia Press.

Koopman, H. (1987). "On the Absence of Case Chains in Bambara." ms. UCLA.

Koopman, H. and D. Sportiche (1988). "Subjects." ms. UCLA.

Loogman, Alfons. 1965. Swahili Grammar and Syntax. Pittsburgh: Duquesne University Press.

Massam, Diane. 1985. "Case Theory and the Projection Principle." Ph.D. dissertation, MIT.

Polome, E. 1967. Swahili Language Handbook. Washington, D.C.: Center for Applied Linguistics.

Reynolds, K. 1989. "The Structure of the Kiswahili Nominal." Ph.D. dissertation, University of Washington.

Rizzi, Luigi. 1990. Relativized Minimality. Cambridge: MIT Press.

Rochemont, M. and C. N. Keach. 1991. "Symmetry, Case and Agreement in Bantu." Unpublished ms., University of British Columbia, Vancouver and Temple University, Philadelphia.

Scotton, C. 1981. "Extending Inalienable Possession: The Argument for an Extensive case in Swahili." Journal of African Languages and Linguistics 3:159-174.

Sportiche, D. 1988. "Conditions on Silent Categories." ms. UCLA.

Vitale, Anthony J. 1981. Swahili Syntax.. Dordrecht: Foris.

Voeltz, E.F.K. 1976. "Inalienable possession in Sotho." Studies in African Linguistics, Supplement 6:255-66.

Whiteley, W.H. 1968. Some Problems of Transitivity in Swahili. London: School of Oriental and African Studies.

Whiteley, W.H. 1972. "Case Complexes in Swahili." Studies in African Linguistics 3:1-46. 
Williams, E. 1981. "Argument Structure and Morphology." Linguistic Review 1:81-114.

Camillia N. Keach

Program in Linguistics

Temple University

Philadelphia, Pennsylvania 19122

Michael Rochemont

Department of Linguistics

University of British Columbia

Vancouver, British Columbia

Canada
[Received September 23, 1992;

revision received March 29, 1992; accepted December 8, 1992;

final version received March 29, 1993] 